\title{
FTR-Based Expert System for Power Generation Units
}

\author{
Naftaly MENN ${ }^{\mathrm{a}, 1}$ and Boris CHUDNOVSKY ${ }^{\mathrm{a}}$ \\ AMS - Advanced Measurement Systems Ltd., IEC-Israel Electric Company, Israel
}

\begin{abstract}
The present expert system addresses the well-known problem existing on each large size boiler of a power generation utility - cleaning of fouling deposition created on the furnace walls and surfaces of heat exchangers. Continuous cleaning, which is a must, especially on large size units operated on fossil fuels, is very cumbersome and time-consuming procedure, mostly performed manually by technical staff sometime assisted by intelligence systems based on neural network. The expert system for cleaning suggested in the present study offers a new approach when the inference engine of the system is oriented to optimization of heat transfer inside the furnace. The target of optimization is maximization of the overall cleanliness factor of the furnace. On-going calculation of local heat transfer in different zones of the furnace is performed in real time by FTR devices positioned in different locations on the furnace wall and measuring continuously the Fouling Thickness and Reflectivity (FTR), along with local temperature of the flame. The system algorithm defines at each measurement cycle the optimal position where the next cleaning should be done and the corresponding signals are transferred by the system electronic circuitry to the controllers of the cleaning measures (the group of soot blowers to be activated). During the last two years our expert system has been successfully implemented on four coil-firing boilers of 500-600 MW on two power stations in Israel.
\end{abstract}

\section{Introduction - Expert systems for Power Generation Utilities}

It is well known that operation of power generation utility is a complicated task requiring on-going management and continuous attention of the engineering and technical staff of the station. Usually, utility is equipped with a great number of sensors and measuring devices allowing to follow after all stages of electricity generation, starting from fuel preparation and supply to the furnace, fuel combustion and heat transfer from the flame to the water converted in steam and delivery of the steam to the turbine where finally electric power is produced. Numerous results of measurements are transferred to the control room of the station (see, for example, description in Ref. [1]) where they are observed and analyzed by the operation technicians, which, according to the received information, decide when and how to interfere in order to provide correct and costeffective electricity production process.

One of the most difficult for analysis is the situation in the furnace where the heat originated in the fuel combustion is transferred to the water/steam mixture. If a fuel mass is not burnt completely, what occurs inevitably when the utility is working with coal or biomass, unburnt particles are deposited on the water tubes surfaces (Fouling), creating

\footnotetext{
${ }^{1}$ Corresponding author, AMS - Advanced Measurement Systems Ltd., IEC- Israel Electric Company, Israel; E-mail: mnaftaly@gmail.com.
} 
an essential thermal resistance to the heat flux. As a result, less heat is absorbed in the furnace tubes and, along with this, the furnace Flue Gas Exit Temperature (FEGT) is increasing which results in slagging, tubes damage, increasing of superheater and reheater spray and growing NOx emissions (see for instance, the graphs of calculations and measurements presented in Ref. [1,2]). To avoid or at least to reduce the negative effect of Fouling the furnace wall and the convection pass surfaces are periodically cleaned using the soot blowing devices which create the strong jets of turbulent air or steam breaking the Fouling deposits. A large size utility normally is equipped with 100 200 soot blowers activated several times every day, so the cleaning procedure is accompanied by significant expenses on water/ steam and electricity of soot blower's operation. Besides of that, soot blowing also causes significant erosion of the water tubes (see again indications in Ref [1,2]). Obviously, it is desirable to decrease the number of cleaning cycles, but then the problem arises of when and where to activate the soot blowers. It is for this reason several expert systems (called sometime as Intelligent soot blowing systems) have been suggested (see Ref. [1-3]), all of them aiming to optimize the cumbersome procedure of boiler cleaning and to make it easier to implement them on power stations.

Two kinds of expert systems are presently in use. The first, described in details in Ref. [1], implement the algorithm based on some rules established in advance while analyzing relations between the boiler performance and activation of soot blowers in different zones of the boiler. The second, (see Ref. [3]), exploits the algorithms of neural network, providing the data base for learning is based on historically collected records while the boiler (of a proper design) was operated at some predefined conditions. Actually, during such learning experiments, similarly to the expert system from Ref. [1], the different groups of soot blowers were activated sequentially and FEGT and other heat transfer parameters have been estimated.

Obviously, both kinds of the expert systems facilitate decision making about cleaning activation, but the usefulness of the recommended procedure is limited because conditions during learning experiment may differ significantly from real situation on the operated facility where the type of fuel, the load of the boiler, the mode of operation and many other factors vary almost every day. Besides of that, as it is evident from description in Ref. [1-3], calculated parameters of heat transfer and the cleanliness are estimated while exploiting complicated models of heat transfer inside the furnace (like those presented in Ref. [4,5]) and do not use the directly measured parameters of the Fouling .This drawback can be avoided by using recently developed hardware - FTR-

Fouling Thickness and Reflectivity measurement system, intended for direct noncontact real time measurement inside the operated furnace (see Ref.[6-8]). Usage of FTR enables to simplify calculation of dynamic heat transfer and renders new possibility for cleaning optimization. The corresponding new expert system is described in the following sections of this paper.

\section{Our Approach}

Keeping in mind that the goal of the expert system is the cleaning of the furnace, we address the cleaning as an optimization process and choose the Overall Cleaning Factor $(\mathrm{CF})$ as a preferable parameter of optimization.

Let the furnace wall be divided to $n$ zone cleaning of which is to be taken into account. Then. the Overall Cleanliness Factor CF can be expressed as a sum of $n$ local 
cleanliness factors $\mathrm{CF}_{\mathrm{i}}$ each of which is defined as the ration of the current heat flux $\mathrm{Q}_{\mathrm{i}}$ transferred to the water/steam mixture to the heat flux $\mathrm{Q}_{\mathrm{oi}}$ when the local fouling is completely removed (clean wall).

$$
C F=\frac{1}{n} \frac{\sum_{i=1}^{n} Q_{i}}{\sum_{i=1}^{n} Q_{0 i}}
$$

In order to calculate the $\mathrm{Qi}$ and $\mathrm{Q}_{0 \mathrm{i}}$ we take into account that at high temperatures developed in the furnace $95 \%$ of heat is transferred by radiation from the flame to the fouling layer and furthermore by conduction through the fouling and through the metal of tube to the water inside the tube The general heat transfer model, described in Ref [4,5], can be significantly simplified for our consideration, as shown on Figure 1. Namely, the temperature distribution in both the Fouling layer and the wall tube is governed by the set of the following heat transfer equations:

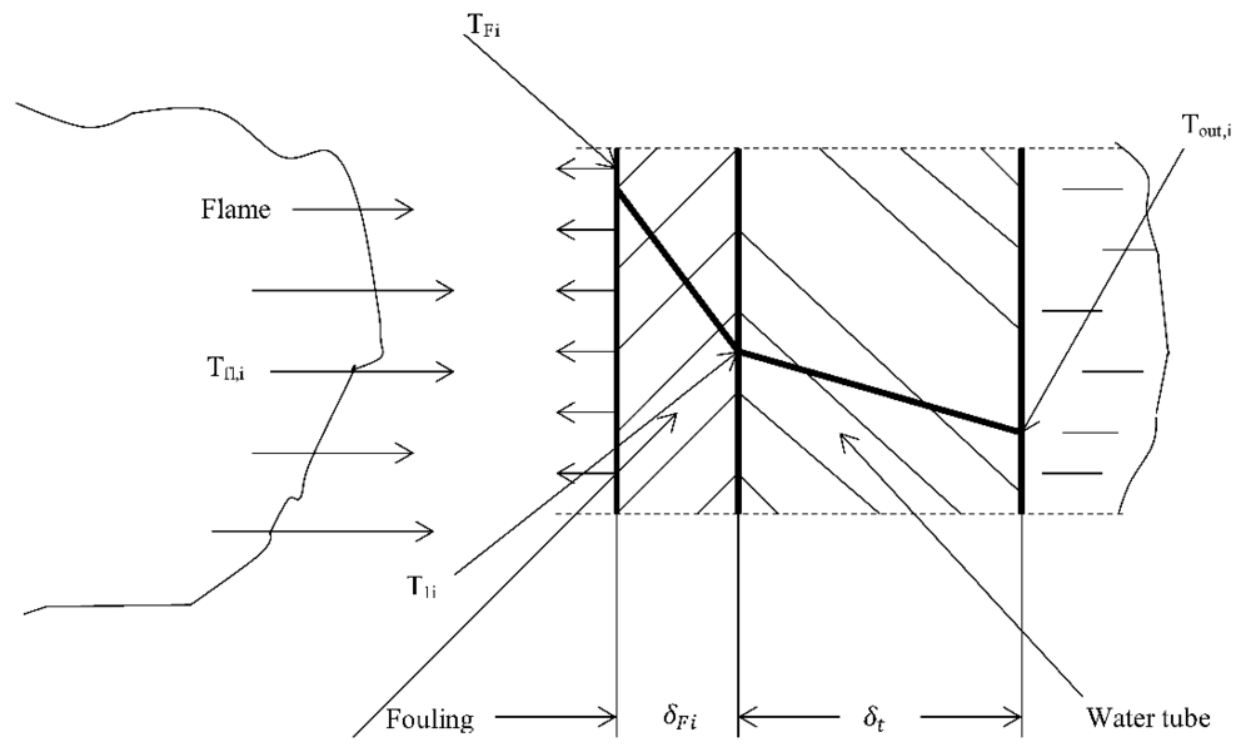

Figure 1. Heat transfer model.

$$
\left(1-R_{F i}\right) \varepsilon \sigma\left(T_{f l, i}^{4}-T_{F i}^{4}\right)=\lambda_{f} \frac{T_{F i}-T_{1 i}}{\delta_{F i}}=\lambda_{t} \frac{T_{1 i}-T_{o u t}}{\delta_{t}}
$$

Eq. (2) allows to get expression of $\mathrm{T}_{1 \mathrm{i}}$ through $\mathrm{T}_{\mathrm{Fi}}$ :

$$
T_{1 i}=T_{F i} \frac{\lambda_{F} / \delta_{F}}{\frac{\lambda_{F}}{\delta_{F i}}+\frac{\lambda_{t}}{\delta_{t}}}+T_{\text {out }, i} \frac{\lambda_{t} / \delta_{t}}{\frac{\lambda_{F}}{\delta_{F i}}+\frac{\lambda_{t}}{\delta_{t}}}
$$

Eq. (3) in the Eq. (2) results in the following non-linear equation with regards to $\mathrm{T}_{\mathrm{Fi}}$ :

$$
\left(1-R_{F i}\right) \varepsilon \sigma\left(T_{f l, i}^{4}-T_{F i}^{4}\right)-T_{F i}\left[\frac{\lambda_{F}}{\delta_{F i}}-\frac{\left(\frac{\lambda_{F}}{\delta_{F i}}\right)^{2}}{\frac{\lambda_{F}}{\delta_{F i}}+\frac{\lambda_{t}}{\delta_{t}}}\right]+T_{\text {out }, i} \frac{\frac{\lambda_{F}}{\delta_{F i}} * \frac{\lambda_{t}}{\delta_{t}}}{\frac{\lambda_{F i}}{\delta_{F i}}+\frac{\lambda_{t}}{\delta_{t}}}=0
$$


which obviously can be solved numerically. Getting $\mathrm{T}_{\mathrm{Fi}}$ allows to calculate the local heat flux $\mathrm{Q}_{\mathrm{i}}$ in zone $\mathrm{i}$ when its reflectivity is $\mathrm{R}_{\mathrm{Fi}}$ and its fouling thickness achieves the value $\delta_{\mathrm{Fi}}$ :

$$
Q_{i}=\lambda_{t} \frac{T_{F i}-T_{o u t, i}}{\delta_{t}}
$$

Now we take into account that just after cleaning $\delta_{F i} \rightarrow 0$ and $T_{F i} \rightarrow T_{1 i}$.

Then, instead of Eq. (4) we receive

$$
\left(1-R_{F i 0}\right) \varepsilon \sigma\left(T_{f l, i}^{4}-T_{1 i, 0}^{4}\right)=\lambda_{t} \frac{T_{1 i, 0}-T_{\text {out }, i}}{\delta_{t}}
$$

Solving (6) with regard of $\mathrm{T}_{1 \mathrm{i}, 0}$, again numerically, we get the values of temperature on the surface of the clean tube which enables to calculate the heat fluxes through the cleaned furnace:

$$
Q_{0 i}=\lambda_{t} \frac{T_{1 i, 0}-T_{\text {out }, i}}{\delta_{t}}
$$

Going back to Eq. (1) we rewrite it as follows:

$$
C F=\frac{1}{n} \frac{\sum_{1}^{n} C F_{i} * Q_{0 i} * W_{i}}{\sum_{1}^{n} Q_{0 i} * W_{i}}
$$

where the local Cleanliness Factors $\mathrm{CF}_{\mathrm{i}}$ are introduced as well as the correction factors $\mathrm{W}_{\mathrm{i}}$ which could be used if additional parameters affecting the impact of the zone $i$ on the Overall Cleanliness Factor should be taken into consideration.

Let at the moment $t_{l}$ the situation on the furnace is described by the local Cleanliness factors

$$
C F_{i}^{\left(t_{1}\right)}=\frac{Q_{i}^{\left(t_{1}\right)}}{Q_{0 i}}
$$

and suppose in the moment $t_{2}$ the cleaning will be done in zone $k$. Then obviously $\mathrm{Q}_{\mathrm{k}}=$ $\mathrm{Q}_{0 \mathrm{k}}$, so that from Eq. (1) for the moment $t_{2}$ we receive

$$
\begin{aligned}
C F^{\left(t_{2}\right)} & =\frac{\sum_{1}^{k-1} C F_{i} * Q_{0 i} * W_{i}+Q_{o k} * W_{k}+\sum_{k+1}^{n} C F_{i} * Q_{0 i} * W_{i}}{n \sum_{1}^{n} Q_{0 i} * W_{i}} \\
& =\frac{\sum_{1}^{k-1} Q_{i} * W_{i}+Q_{0 k} * W_{k}+\sum_{k+1}^{n} Q_{i} * W_{i}}{n \sum_{1}^{n} Q_{i} * W_{i}}=C F_{\text {new }}^{\left(t_{2}\right)}
\end{aligned}
$$

The last expression shows what would be the Cleanliness Factor of the furnace if at $t_{2}$ only area number $k$ will be cleaned. Repeating calculations for all $k$ from 1 to $n$ and comparing the results we can find the zone which corresponds to the maximum new Cleanliness Factor, in other words the cleaning in this area will improve the heat transfer more than cleaning of any other zone and therefore can be defined as optimal (of course for this very moment of time):

$$
k_{\text {opt }}: \max \left\{C F_{\text {new }}^{\left(t_{2}\right)}\right\}
$$


The time difference $\left(t_{2}-t_{1}\right)$ is the duration of cleaning cycle after which the optimization procedure should be activated again and so on, meaning that the results of (11) renders the full sequence of locations recommended for cleaning. This recommended sequence can be either used for manual operation or implemented automatically, as described in the following sections.

\section{Data base and the Hardware}

As it can be seen from the previous description, the suggested expert system requires continuously performed calculation of heat transfer inside the furnace. Parameters needed for calculation vary from zone to zone (the fouling thickness $\delta_{\mathrm{FI}}$ and reflectivity $\mathrm{R}_{\mathrm{Fi}}$, and the local temperature of the flame $\mathrm{T}_{\mathrm{FLi}}$ ) and also are time dependent. Therefore, the data base for this expert system cannot be collected in advance, but have to be measured directly and in real time.

In order to carry out these direct measurements during normal operation of the boiler a special technique and a special hardware called FTR-Fouling Thickness and Reflectivity system (see Ref. [ 6,7]), have been exploited. It comprises a number of specially designed devices positioned in different zones of the furnace wall, each having a moving probe which is introduced into the furnace through a small opening, $6 \mathrm{~mm}$ by $12 \mathrm{~mm}$, on the membrane between the wall tubes. The probe is extended into the furnace for a short time of measurement (up to $2 \mathrm{sec}$ ) and then is withdrawn outside. Each FTR device includes the light source (a small laser diode) creating a light spot on the surface of Fouling which is imaged on the video detector. Position of the spot image on the detector renders information about the Fouling thickness whereas intensity of light reflected back to the probe and incident on the detector gives information about the local reflectivity of the Fouling before and after the cleaning.

Recently an advanced FTR device was suggested (see Ref. [8]) which, along with the Fouling sensor, comprises also the flame temperature sensor. Using the principle of two wavelengths optical pyrometer, this sensor enables to measure the local temperature of the flame and the flame local apparent emissivity.

A full expert system includes a number of FTR devices, each with a processing unit, all of them being interfaced to the central computer where the algorithm of optimization described in section 2 is continuously run and analyzed at every cleaning cycle (usually each $30 \mathrm{~min}$ ).

Figure 2 demonstrates schematics of the FTR device and its accessories, all are operated by the suggested expert system.

\section{Implementation}

The expert system described above has been implemented on two power stations in Israel. Two coal firing boilers on each station have been equipped with this expert systems- 575 MW tangential firing boilers and $550 \mathrm{MW}$ opposite firing boilers. On both stations optimal cleaning was first realized manually, while decision making was assisted by the system algorithm presented in section 2 above, and later it was operated fully automatically when the calculation results from the system server were transferred to the electronic controllers activating the soot blowers of the furnace. 


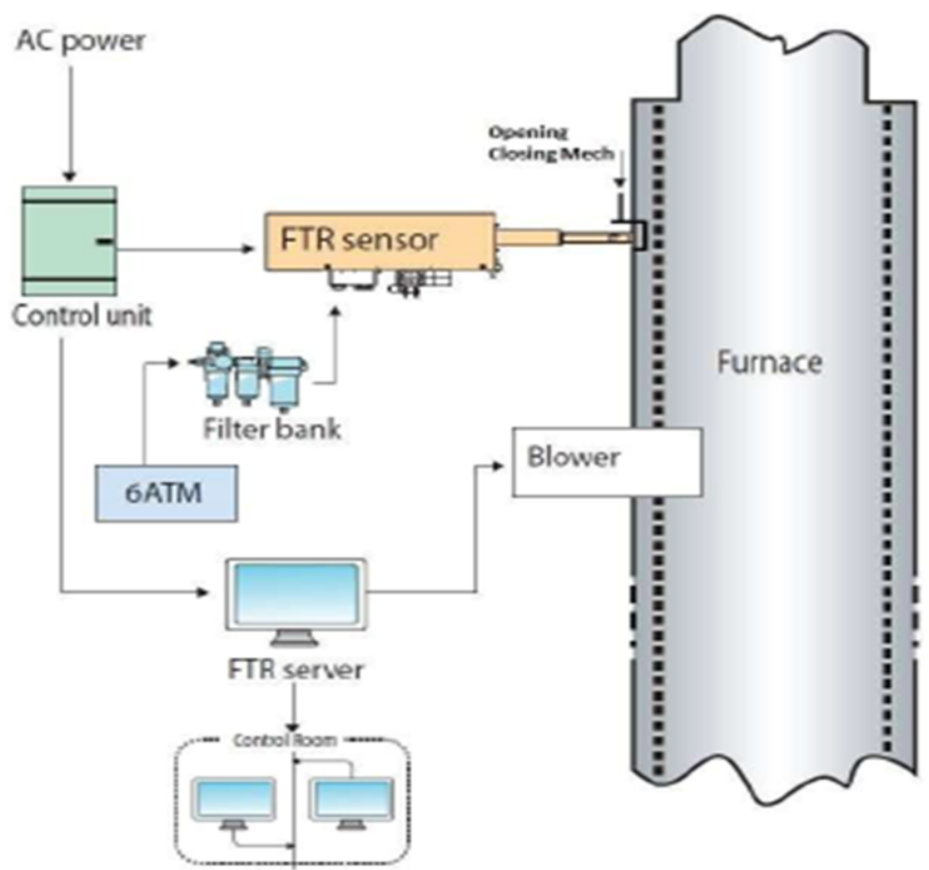

Figure 2. Schematics of FTR hardware on the furnace wall.

Automatic operation of the expert system on these two power stations is continuously working during the last two years. In the course of this period of time it was realized that several additional rules should be added to the main algorithm of the system allowing to stop automatic cleaning when regime of the boiler is changed drastically or in order to avoid approaching to some critical situations. Execution of the rules is either examined by the system server or transferred to the system processor as a chain of messages sent from the station control room.

Figure $3 \mathrm{a}$ and $3 \mathrm{~b}$ demonstrates how effective is the cleaning optimization governed by the automatic expert system. On Figure 3a are presented the measurement results (he Fouling thickness and hemispherical reflectivity) before activation of the FTR system, the red lines indicate when the soot blowers were activated according to the procedure existing on the power plant. Figure $3 \mathrm{~b}$ shows how drastically the program of cleaning was changed using optimal cleaning by FTR system - the frequency of soot blower's activation was reduced more than two times without significant growth of the Fouling deposition thickness and reflectivity and even getting improved Cleanliness Factor (CF initial value was 0.7 while the final value achieved 0.85 ). 


\section{The FTR system generates unique data:}

Sootblowing sequence - without FTR, with Heat Flux Sensors, Cleanliness Factor $=0.7$

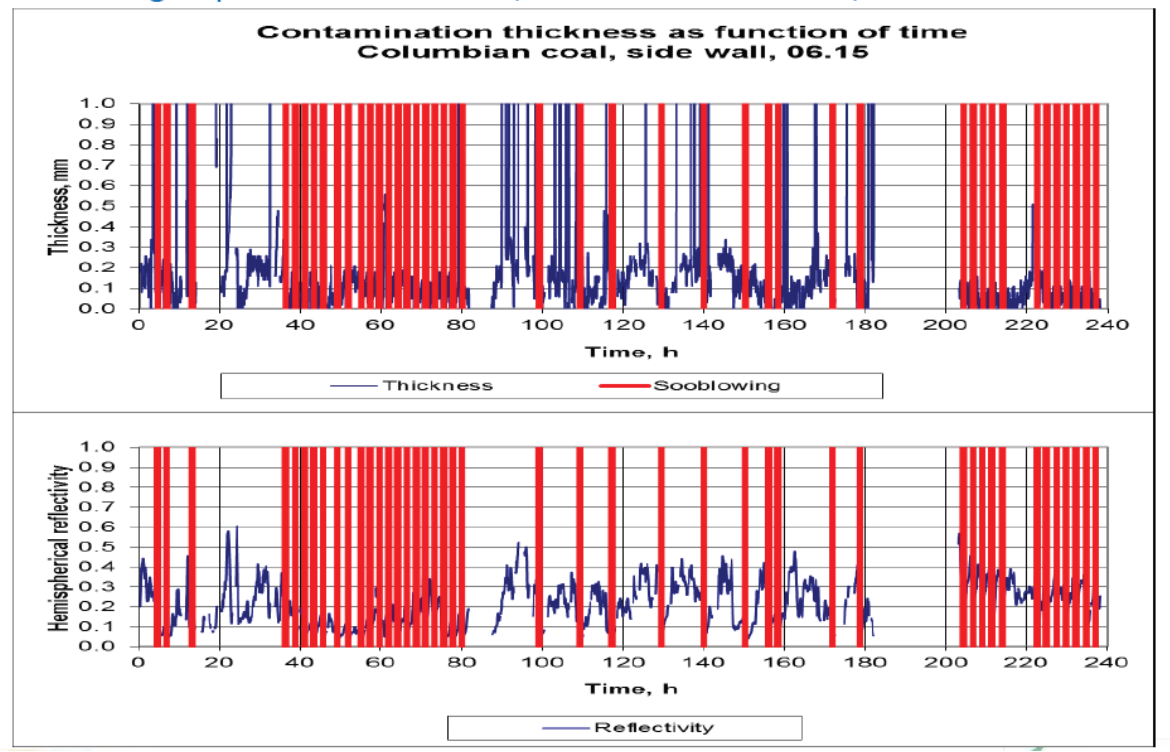

Figure 3a. Measurement results without FTR.

\section{Soot blowing sequence Controlled by the FTR System - Cleanliness Factor $=0.85$}

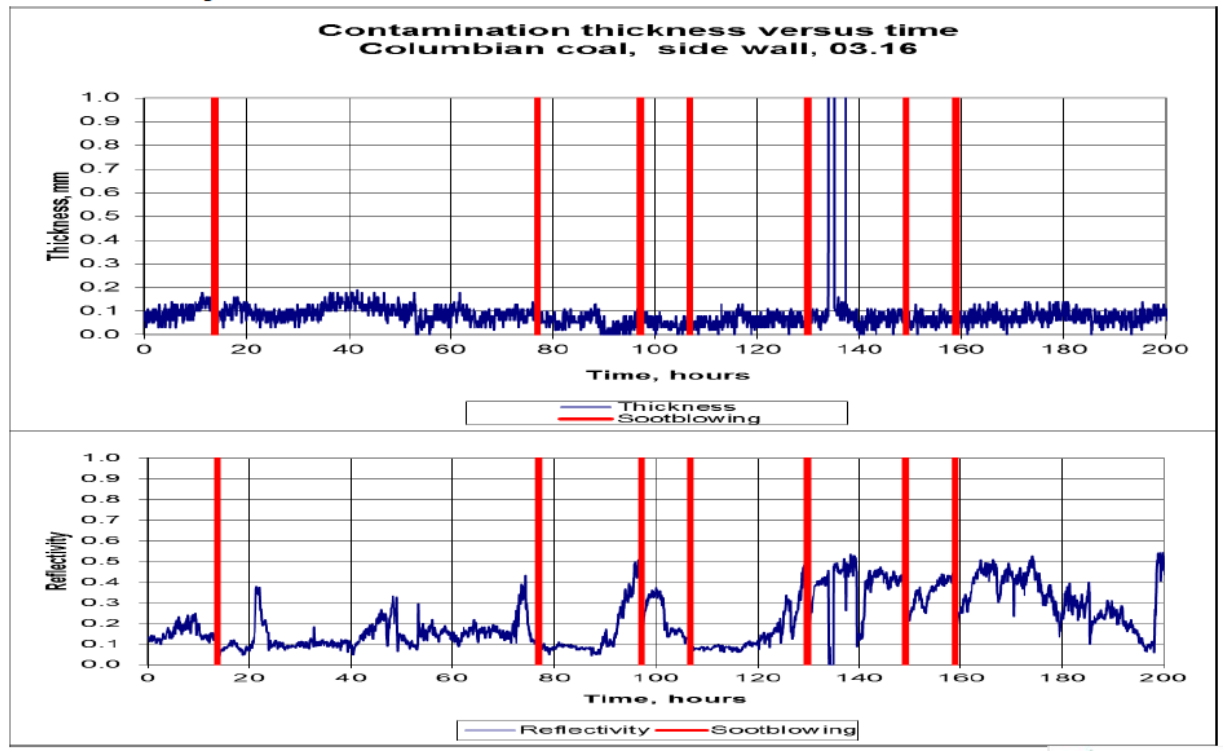

Figure 3b. Measurement results with activated FTR. 


\section{Summary}

A new expert system allowing automatic optimization of the cleaning procedure in the furnace of a coal firing boilers is suggested. The system database is created in real time while measuring the major heat transfer parameters - the flame temperature and emissivity along with fouling deposition thickness and reflectivity. The measurements are carried out by specially designed FTR devices based on electro-optical arrangements allowing non-contact direct measurement of major parameters of heat transfer inside the furnace. The main algorithm of the expert system performs optimization procedure at each cleaning cycle with regard to Overall Cleanliness Factor of the furnace.

The system was implemented on two power station in Israel, where optimal cleaning enables to get significant reduction of expenses on operation of the soot blowers and improves performance of the boilers (higher $\mathrm{CF}$ ).

\section{List of Symbols}

$\mathrm{CF}$ - Cleanliness Factor

$\mathrm{Q}$ - heat flux, $W / m^{2}$

$\mathrm{T}$ - absolute temperature in ${ }^{0} \mathrm{~K}$

$\varepsilon$-apparent emissivity of the flame

$\delta$ - thicknes of the fouling layer or a tube wall, $m$

$\mathrm{R}=$ reflectivity of fouling deposition

$\lambda$ - thermal condactivity, $W /(m . K)$

$\sigma-$ Stefan - Bolzman constant

$\mathrm{W}$ - factor of relative influence on heat transfer

$\mathrm{n}-\mathrm{a}$ number of zones at the furnace wall, taken into consideration

\section{Subscript}

fl -- flame

$\mathrm{F}$ - fouling

$\mathrm{t}=$ water tube

$\mathrm{i}$ - current value in zone $\mathrm{i}$

$0 \mathrm{i}$ - value in zone $i$ just after cleaning

\section{References}

[1] Custer J, Fuller TA. Performance improvements through intelligent sootblowing optimization at longview power. Power Engin. 2017; 121(2).

[2] Piboontum SJ, Swift SM, Conrad RS. Boiler performance improvement due to intelligent soot blowing utilizing real-time boiler modeling UP Boilers. Presented to Electric Power 2005, April 5-7; Chicago, Illinois, USA.

[3] Shah S, Bergemann C, Breeding C. Implementation of intelligent soot blowing. Clyde Bergemann, Inc. Electric Power 2004; Baltimore, Maryland, March 30 - April 1, 2004.

[4] Zhang YG, Li QH, Zhou H. Heat transfer calculation in Furnaces. In book: Theory and calculation of heat transfer in Furnaces, Academic Press, December, 2016. 
[5] Makarov AN. Calculations of heat transfer in the furnaces of steam boilers according to the laws of radiation of gas volumes. Chapter 6 in: Heat transfer- Models, Methods and Applications. IntechOpen, 2018, p.111-140.

[6] Naftaly M, Joseph K. A method and apparatus for measurement of thickness and reflectivity of fouling deposits on tubes in a Pulverized coal -firing Furnace. US patent No. 9,709,384, July 18, 2017.

[7] Menn N, Chudnovsky B. New technology for monitoring fouling deposition in coal-firing boilers. Intern. J. Electr. Heat Generation VGB PowerTech. 2016; 6: p.65.

[8] Menn N, Krimerman J. Measurement and Monitoring of the local flame temperature, flame apparent emissivity, fouling thickness and fouling reflectivity in the furnace of a coal and/or biomass firing boiler. Provisional Patent Application, 63/259,642, 08/02/2021, USA. 